OPEN ACCESS

Edited by:

Menno R. Kruk,

Leiden University, Netherlands

Reviewed by:

Sietse De Boer,

University of Groningen, Netherlands

Kumi Kuroda

RIKEN Brain Science Institute (BSI),

Japan

*Correspondence:

Dayu Lin

dayu.lin@nyumc.org

Received: 15 September 2017 Accepted: 28 November 2017

Published: 20 December 2017

Citation:

Hashikawa Y, Hashikawa K,

Falkner AL and Lin D (2017)

Ventromedial Hypothalamus and the

Generation of Aggression.

Front. Syst. Neurosci. 11:94

doi: 10.3389/fnsys.2017.00094

\section{Ventromedial Hypothalamus and the Generation of Aggression}

\author{
Yoshiko Hashikawa ${ }^{1}$, Koichi Hashikawa ${ }^{1}$, Annegret L. Falkner ${ }^{1}$ and Dayu Lin ${ }^{1,2,3 *}$ \\ ${ }^{1}$ Neuroscience Institute, New York University School of Medicine, New York University, New York, NY, United States, \\ ${ }^{2}$ Department of Psychiatry, New York University School of Medicine, New York University, New York, NY, United States, \\ ${ }^{3}$ Center for Neural Science, New York University, New York, NY, United States
}

Aggression is a costly behavior, sometimes with severe consequences including death. Yet aggression is prevalent across animal species ranging from insects to humans, demonstrating its essential role in the survival of individuals and groups. The question of how the brain decides when to generate this costly behavior has intrigued neuroscientists for over a century and has led to the identification of relevant neural substrates. Various lesion and electric stimulation experiments have revealed that the hypothalamus, an ancient structure situated deep in the brain, is essential for expressing aggressive behaviors. More recently, studies using precise circuit manipulation tools have identified a small subnucleus in the medial hypothalamus, the ventrolateral part of the ventromedial hypothalamus (VMHvI), as a key structure for driving both aggression and aggression-seeking behaviors. Here, we provide an updated summary of the evidence that supports a role of the VMHvl in aggressive behaviors. We will consider our recent findings detailing the physiological response properties of populations of $\mathrm{VMHvl}$ cells during aggressive behaviors and provide new understanding regarding the role of the VMHvl embedded within the larger whole-brain circuit for social sensation and action.

Keywords: VMHvl, aggression, mouse, neural activity, neuromodulation

\section{AN ESSENTIAL ROLE FOR THE VMHVL IN AGGRESSIVE BEHAVIORS}

Aggression is an innate social behavior essential for resource competition, settling disputes, defense, and protecting kin. It is a prevalent behavior across many species, including humans, and in a variety of species including cats, rats, chickens, and monkeys, electrical stimulation studies have demonstrated a causal role of the medial hypothalamus in expressing aggressive behaviors (Putkonen, 1966; Siegel and Skog, 1970; Lipp and Hunsperger, 1978; Kruk et al., 1979, 1983; Lammers et al., 1988; Siegel and Pott, 1988; Siegel et al., 1999; Halasz et al., 2002; Nelson and Trainor, 2007). Recent studies using more precise functional manipulation tools in mice have identified the ventrolateral part of the ventromedial hypothalamus (VMHvl), a small subnucleus in the medial hypothalamus, as a key region to drive inter-male aggression (Table 1). Silencing this area abolishes naturally occurring inter-male attack whereas optogenetic activation of the VMHvl but not its surrounding regions promotes the attack of suboptimal targets, including females and inanimate objects (Lin et al., 2011). The VMHvl is highly enriched in hormone receptors, including estrogen receptor alpha (Esr1) and progesterone receptor (PR) which co-express in nearly $100 \%$ of cells. Several converging studies have recently demonstrated that these hormone receptorexpressing cells appear to be key populations for mediating aggression in both males and females 
(Yang et al., 2013, 2017; Lee et al., 2014; Hashikawa et al., 2017). Killing PR+ cells or inhibition of the Esr1+ cells suppressed naturally occurring aggression (Yang et al., 2013; Lee et al., 2014; Hashikawa et al., 2017). Conversely, optogenetic activation of the VMHvl Esr1+ cells elicited immediate attack and pharmacogenetic activation of the $\mathrm{PR}+$ cells increases the frequency of attack (Lee et al., 2014; Hashikawa et al., 2017; Yang et al., 2017). Furthermore, the aggression-promoting effects of activating VMHvl PR+ cells were also observed in castrated males and also in males with defective olfactory inputs, suggesting that the VMHvl activation can "override" normal hormone and sensory requirements for aggression (Yang et al., 2017).

While these studies clearly implicated hormone-receptive populations in the generation of aggression, the role of the $\mathrm{VMHvl}$ in this behavior remained unclear. Is the VMHvl simply an "attack generator" or does it also promote flexible aggression seeking behaviors that lead to attack? As evidence for aggression-seeking behavior, it has been observed behaviorally from fish to primates that certain individuals will develop a strong preference for the context where they attacked a conspecific (Meisel and Joppa, 1994; Martinez et al., 1995; Golden et al., 2016) and will voluntarily seek the opportunity to attack a conspecific (Thompson, 1963; Cherek et al., 1973; Turnboug and Lloyd, 1973; Fish et al., 2002, 2005; May and Kennedy, 2009; Mitani et al., 2010; Golden et al., 2017). To test the role of the VMHvl in aggression seeking, we designed a self-initiated aggression-seeking (SIA) task during which the animals learn to voluntarily nose poke to gain access to a weaker male intruder (Falkner et al., 2016). Over weeks of training, the majority of trained males exhibited task-dependent learning. These animals demonstrated a clear preference for the nose port associated with the weak intruder, poked it repeatedly and attacked the intruder immediately after its introduction (Figure 1). We found that lowlevel optogenetic activation of the VMHvl cells reliably reduced the animals' latency to nose poke for an opportunity to attack. Conversely, inhibiting the VMHvl suppressed nose poking for the chance to attack but not for water reward, demonstrating a role for the VMHvl in aggression seeking in addition to attack (Falkner et al., 2016).

It is important to note that this area is not exclusively implicated in aggressive behaviors. In addition to aggression, the VMHvl is also well-known for its essential role in female sexual behaviors and to a lesser extent, in male sexual behaviors (Pfaff and Sakuma, 1979a,b; Yang et al., 2013; Lee et al., 2014; Hashikawa et al., 2017). Furthermore, the VMHvl may also mediate behaviors against an aggressor: immediate early gene mapping experiments have revealed strong activation of the area in subordinate animals after social defeat (Kollack-Walker et al., 1997; Motta et al., 2009; Pan et al., 2010; Silva et al., 2013) and re-activation of the defeat induced Fos population in the VMHvl elicits fearful responses (Sakurai et al., 2016). Thus, the VMHvl likely mediates multiple social behaviors and future studies will need to address how factors including social experience, hormonal state, and behavioral context influence which behaviors are generated.

\section{THE ENCODING OF AGGRESSION-RELATED INFORMATION IN THE VMHVL}

Among identified aggression-related circuits in the brain, the VMHvl is currently the best understood area, due in large part to our characterization of the response properties of neurons during social behaviors. We have performed extensive electrophysiological recording in the VMHvl in freely-moving, socially-interacting animals (Lin et al., 2011; Falkner et al., 2014, 2016; Wong et al., 2016). Based on these data, we propose that VMHvl cells encode at least three features of aggressionrelated information: (1) the overall aggressive state of the animal (motivation); (2) the detection of aggression-provoking sensory cues (sensation); and (3) the initiation and execution of attack and aggression-seeking behaviors (action) (Figure 2). We hypothesize that the aggressive state is encoded as the baseline spiking activity of the VMHvl cells whereas the sensory information and the motor actions are encoded by acute changes in VMHvl activity.

\section{Aggressive Arousal State}

Upon the intruder introduction, VMHvl activity quickly increases and is maintained at a high level. This elevation in spontaneous activity is not associated with any particular behavior and can account for $\sim 50 \%$ of the total VMHvl firing rate increase (Lin et al., 2011; Falkner et al., 2016; Hashikawa et al., 2017). In addition, VMHvl activity can remain at an elevated state for minutes after the intruder removal (Falkner et al., 2014). Increased VMHvl activity after intruder removal coincides with a heightened aggressive state. If a second intruder is presented shortly after removing the first intruder, both the latency to attack decreases and the probability of attack increases (Potegal et al., 1996). As further demonstration of this, in tests of the self-initiated aggression task, after the animal learned the task contingency, similar sustained increase in spiking activity was observed after the nose poking apparatus was introduced into the cage of the intruder but before any nose poking or attack (Unpublished data by Annegret Falkner). Consistent with a heightened aggressive state of the animal during the selfinitiated aggression task, the resident male typically attacks the intruder immediately after the intruder becomes available. These electrophysiological and behavioral observations lead us to hypothesize that the spontaneous activity of the VMHvl signals the general aggressive state of the animal.

This property may be common to the hypothalamus and associated neural circuit. Other internal states such as hunger and thirst have also been shown to be encoded by the spontaneous activity of specific populations of neurons. For example, AgRP neurons in the arcuate nucleus promote feeding and food seeking when artificially activated and these neurons show sustained increase in neural activity in food deprived animals (Aponte et al., 2011; Krashes et al., 2011; Betley et al., 2015; Chen et al., 2015). Similarly, subfornical organ (SFO) neurons can promote drinking and seeking for water when artificially activated and show sustained increase in spontaneous activity in water deprived 
TABLE 1 | VMHVl is essential for aggression.

\begin{tabular}{|c|c|c|c|c|c|c|}
\hline & Manipulation & Sex & Population & Test & Behavior & References \\
\hline \multirow[t]{3}{*}{ Gain of function } & ChR (20 ms, 20 Hz) & Male & VMHvl & R-I test & Attack & $\begin{array}{l}\text { Lin et al., 2011; Falkner } \\
\text { et al., } 2016\end{array}$ \\
\hline & ChR $(20 \mathrm{~ms}, 20 \mathrm{~Hz})$, low intensity & Male & VMHvl Esr1+ & R-I test & Close investigation, mounting & Lee et al., 2014 \\
\hline & DREADDq (CNO, i.p. injection) & Male & VMHvl PR+ & R-I test & Increase attack frequency & Yang et al., 2017 \\
\hline \multirow[t]{4}{*}{ Loss of function } & GluCL (IVM, i.p. injection) & Male & VMHvl & R-I test & Reduce attack & Lin et al., 2011 \\
\hline & DREADDi (CNO, i.p. injection) & Male & VMHvl & R-I test & Reduce attack & Falkner et al., 2016 \\
\hline & NpRH (continuous light) & Male & VMHvl Esr1+ & R-I test & Block attack & Lee et al., 2014 \\
\hline & Caspase 3 (ablation) & Male & VMHvl PR+ & R-I test & Reduce attack & Yang et al., 2013 \\
\hline
\end{tabular}

A summary of functional manipulation experiments that support an essential role of the VMHVI in conspecific aggression.

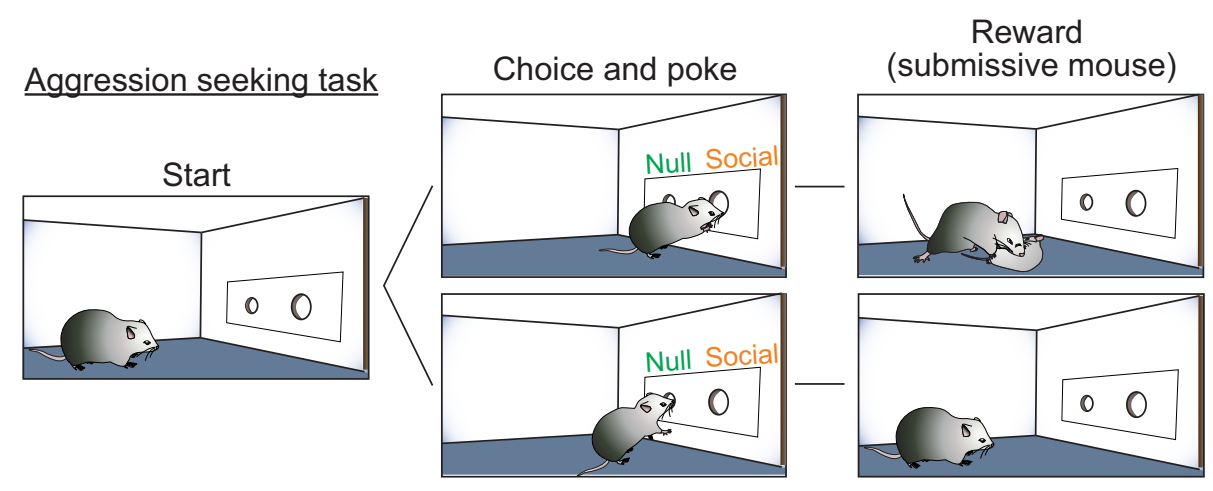

FIGURE 1 | Self-initiated aggression seeking task is utilized to study appetitive phase of aggression. Schematic illustration of the self-initiated aggression seeking task. By poking the social poke, subjects gain access to a submissive intruder and attack.

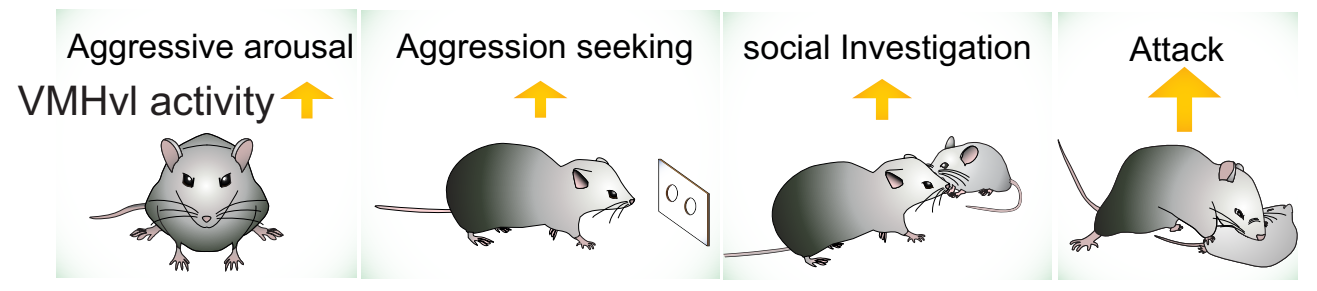

FIGURE 2 | The activity of VMHvl increases during social investigation, aggression seeking and attack, and when the animal is at a heightened aggressive state.

animals (Oka et al., 2015; Zimmerman et al., 2016). While in those cases, changes in spontaneous activity are caused by changes in interoceptive physiological signal, in our experimental condition, elevation in $\mathrm{VMHvl}$ spontaneous activity is triggered by external cues, such as conspecific intruders or aggressionassociated object. However, an aggressive internal state can also be signaled internally through experience. For example, male mice that repeatedly encounter a male intruder at the same time of the day learn to anticipate the fighting as indicated by their increase in heart rate and body temperature prior to the scheduled fighting time (Tornatzky et al., 1998). Whether the internally generated aggressive state is also accompanied and/or caused by an increase in spontaneous $\mathrm{VMHvl}$ activity remains to be confirmed.

\section{Aggression-Provoking Olfactory Cues}

VMHvl cells also robustly respond to olfactory cues associated with aggression-provoking stimuli (Falkner et al., 2014). During 
investigation of male intruders, male-responsive VMHvl cells acutely increase activity from an already elevated baseline. Moreover, when recorded males investigated urine from the intruder, $\mathrm{VMHvl}$ activity also increased in a subpopulation of cells (Lin et al., 2011; Falkner et al., 2014). Urine is a rich source of pheromones and carries important information regarding the sex, physiological, and social status of the animal (Dulac and Torello, 2003). Several volatiles and major urinary proteins have been identified in male mouse urine that can promote aggression when applied onto the intruder mouse (Novotny et al., 1985; Chamero et al., 2007). As a demonstration of this, castrated male intruders, whose urine contains fewer critical volatiles are less likely to be attacked by resident male mice (Mugford and Nowell, 1970) and urine from castrated male mice generate less activity from VMHvl cells in comparison to intact male mouse urine (Falkner et al., 2014). Male mice also rarely attack females, and female urine increases activity in only a small subpopulation of VMHvl neurons in aggressive males (Falkner et al., 2014).

\section{Aggressive Actions}

During free social interactions, the most prominent activity increase observed in VMHvl cells is from attack itself. Activity in responsive cells rises prior to attack $(\sim 1 \mathrm{~s})$, peaks at the onset of attack, sustains throughout the duration of attack, and quickly drops to the baseline level at the behavioral offset (Falkner et al., 2014). Importantly, movements unrelated to attacking do not correlate with or predict VMHvl activity (Falkner et al., 2014). In addition, several complimentary lines of evidence suggest that this increased activity during attack cannot be simply accounted by the increased activity from sensory cues. First, the response during attack is higher than the responses during investigation that precedes attack (Falkner et al., 2014; Hashikawa et al., 2017). Second, when we compare the isolated aggression trials (attack not preceded or followed by attack) and investigation trials (investigation not followed or preceded by attack), we find that attack responses are significantly higher during these isolated attack trials (Hashikawa et al., 2017). Third, in a linear regression model that explores the relationship between various behavioral parameters and VMHvl cell activity, we found that the inclusion of a "latency to attack" parameter can significantly improve model fit in a subpopulation of cells beyond what can be accounted for considering the distance between animals (an estimate of sensory input) and the movement velocity of the animal. This data quantitatively supports the hypothesis that the VMHvl activity carries information regarding the initiation of attack independently of these external cues (Falkner et al., 2014). Furthermore, using the self-initiated aggression seeking task as a way to separate actions associated with seeking and attack, we found that a subset of VMHvl cells increase spiking activity prior to and during nose poking once the animal learned the association between nose poking and future attack (Falkner et al., 2016). This shows that the VMHvl cells not only signal the initiation of physical attack but also flexible learned actions that lead to future attack.

Aggressive state, aggression-provoking sensory cues, and aggressive actions are encoded by highly overlapping populations of VMHvl cells. Approximately half of the VMHvl cells that respond during attack and investigation showed sustained increase in spontaneous activity in the presence of intruder (Lin et al., 2011). The cell responses during attack and social investigation are significantly correlated (Falkner et al., 2014). Approximately $80 \%$ of cells that increase activity during aggression seeking also increase activity during attack (Falkner et al., 2016). Thus, the activity of a single VMHvl cell at any given moment can encode multiple aspects of aggression-related information and these signals may be linearly summed to create the observed response profile.

Other hypothalamic subregions may encode similar multifaceted responses for other social behaviors. One well-studied example of this is the responses of cells in the medial preoptic area (MPOA) during sexual behaviors. In vivo extracellular recording from the MPOA in freely moving rats revealed that MPOA cells show sustained increase in activity after female introduction as well as acute increase in activity during female investigation and specific sexual actions, such as pursuing, mounting, and intromission (Oomura et al., 1983; Horio et al., 1986; Shimura et al., 1994). Additionally, an acute increase in the MPOA cell activity was observed every time when the male operated a lever to bring a female closer to him (Oomura et al., 1988). Thus, similar to VMHvl activity change during aggression, the MPOA cells signal the animal's sexual arousal, detection of sexual arousal cues, and specific preparatory and consummatory sexual actions. Taken together, we speculate that the same general coding principles are employed by hypothalamic networks to represent sensory, arousal (motivation) and action-related information essential for social behaviors.

\section{Experience-Dependent Changes in VMHvl Cell Responses}

Mounting evidence now suggests that the response properties of VMHvl neurons are not fixed as would be in a "hard-wired" innate circuit, but instead are constantly updated. Recently, Remedios et al. used microendoscopic calcium imaging to examine changes in VMHvl cell activity over days as the recorded males encountered male and female intruders and obtained social experience (Remedios et al., 2017). While the VMHvl responses during male and female investigation heavily overlap initially in naïve unexperienced males, brief sexual experience with females caused significant divergence of the VMHvl cell responses. Importantly, this divergence only occurred when animals started to show mounting and fighting, suggesting a potential causal link between the change in neural responses and the selection of appropriate social actions. Additionally, we also observed changes in VMHvl activity over the training of the selfinitiated aggression seeking task (Falkner et al., 2016). In early training phase before the animals made the association between nose poking and the opportunity to attack, little response of VMHvl cells during poking was found. As the training went on and animals successfully learned the task contingency, VMHvl cells showed clear activity increase prior to, during and after the nose poking, supporting the capacity of VMHvl cells to change responses with experience. 
Experience-dependent changes in VMHvl activity also appear to alter the efficacy of attack initiation. In early electric stimulation experiments in rats, it was found consistently that repeated attack induced by electric stimulation reduced the amount of current required to elicit attack in subsequent testing days (Kruk, 2014). This threshold-lowering effect requires the attack itself (i.e., it cannot be induced via stimulation in isolation) (Kruk et al., 1979; Kruk, 2014). More recently, Yang et al. examined the reliability of $\mathrm{VMHvl}$ activation-induced aggression in animals with different experience and under different testing environment (Yang et al., 2017). They expressed an engineered ligand $(\mathrm{CNO})$ gated $\mathrm{Gq}$ coupled receptor, DREADDq, in the VMHvl and examined the CNO injection induced attack in animals that are single- vs. group-housed and in home territory vs. foreign territory. They found that while attack can be reliably chemogenetically induced in single-housed mice in both home and foreign territory, this same manipulation is only effective in inducing attack in group housed males when tested in home territory. The difference in attack induction efficacy between single-housed and group-housed animals is likely due to either to differences in the physiological properties of the VMHvl itself, or to changes in its inputs. In the VMHvl itself, intrinsic excitability may be higher in singly-housed animals than group-housed animals and VMHvl neurons in singlyhoused animals are likely to fire more readily when activated using DREADDq. Alternatively, cues related to foreign territory may cause a stronger suppression of VMHvl cells in grouphoused animals and prevent the cells from spiking in a foreign territory. Consistent with this second idea, a high efficacy of stimulation-evoked attack can be "revealed" in group-housed animals in a foreign environment when the olfactory inputs were blocked (Yang et al., 2017). Future experiments that examine the physiological and synaptic properties of VMHvl cells from animals with different experience and aggression level will help elucidate the dynamic range of VMHvl cell physiological properties and whether hyper-excitability of VMHvl cells could also be related to the exaggerated aggression observed under certain pathological conditions in human patients and animal models, such as autism, borderline personality disorder, and posttraumatic stress disorder (Kanne and Mazurek, 2011; JiangXie et al., 2014; Wells et al., 2016).

\section{MOLECULAR AND CIRCUIT MECHANISMS FOR DRIVING AGGRESSION-RELEVANT VMHVL ACTIVITY}

\section{Circuits for Olfactory Input}

The VMHvl responses that signal aggressive state, sensory detection, and aggressive action may result from independent sources of activity which include both sensory inputs and changes in neuromodulatory tone. Among these potential molecular and synaptic drivers, the VMHvl responses to the olfactory cues are the best understood since pathways that convey olfactory information have been previously identified (Figure 3A). The $\mathrm{VMHvl}$ receives converging volatile and pheromone information from the medial amygdala (MEA) and bed nucleus of stria terminals (BNST) (Canteras et al., 1994). Volatile information passes through the main olfactory epithelium, main olfactory bulb, posterolateral cortical amygdala ( $\mathrm{plCOA}$ ) and arrives at the MEA and BNST whereas pheromone information is relayed through the vomeronasal organ (VNO), accessory olfactory bulb (AOB) and then also reaches the MEA and BNST (Hashikawa et al., 2016). Recent tracing studies also suggest that MOB mitral and tufted cells may directly project to the MEA (ProSistiaga et al., 2007; Kang et al., 2009, 2011). Regardless, converged volatile and pheromone information at the MEA and BNST can then reach the VMHvl either directly or indirectly through the ventral part of the premammillary nucleus (PMv), a hypothalamic region that is situated posterior to the $\mathrm{VMHvl}$ (Canteras et al., 1992a, 1995; Pardo-Bellver et al., 2012). PMv inputs are likely to be critical for the responses of VMHvl cells to olfactory cues: immediate early gene mapping showed that the PMv is strongly activated by the odor cues from conspecifics (Donato et al., 2010; Soden et al., 2016) and when the PMv is inactivated, $\mathrm{VMHvl}$ response to an aggression-provoking conspecific is largely eliminated (Motta et al., 2013).

\section{Neuromodulatory Inputs and Aggressive State}

While the increase in the VMHvl spontaneous spiking during a heightened aggressive state may be partly due to the sensory inputs from the intruder, this is unlikely to account for all activity change, since these changes persist following the removal of aggressive stimuli (Lin et al., 2011; Falkner et al., 2014). We speculate that a relatively slow neuromodulatory or neuroendocrine mechanism may also contribute to the change in spontaneous activity (Figure 3B). Consistent with this hypothesis, in vitro extracellular slice recording demonstrated that VMHvl cells respond to a variety of bath-applied neuromodulators, including acetylcholine, norepinephrine, serotonin, and dopamine (Kow and Pfaff, 1985). Among them, serotonin and dopamine are mainly inhibitory possibly due to the strong expression of $\mathrm{Gi}$-coupled serotonin receptor $1 \mathrm{~A}$ (5HT1A) (Wright et al., 1995) and dopamine receptor D2 (D2R) in the area (Moss et al., 1985; Bouthenet et al., 1991; Weiner et al., 1991). In contrast, norepinephrine elicits both excitatory and inhibitory responses in the VMHvl cells, possibly due to the strong expression of $\mathrm{Gq}$ coupled $\alpha_{1 \mathrm{a}}$-adrenergic receptor (Day et al., 1997) and to a lesser extent Gi coupled $\alpha_{2 c}$-adrenergic receptor (Wang et al., 1996). The effect of acetylcholine on the VMHvl cells is mainly excitatory, likely through both nicotinic and muscarinic acetylcholine receptors. More specifically, VMH cells express $\alpha 7$ nicotinic receptor (Clarke et al., 1985; Baddick and Marks, 2011) that has high $\mathrm{Ca} 2+$ permeability, and $\mathrm{Gq}$ coupled M1, M3, and M5 and to a less extent Gi coupled M2 and M4 (www.brain-map.org, experiment ID 73907497, 70560343, 79912556, 79591641, and 75826557) (Levey, 1993; Levey et al., 1994). The Muscarinic activation can generate plateau potential and persistent spiking activity in cortex and hippocampus (Egorov et al., 2002) and thus could be particularly relevant for generating the increased spontaneous activity in VMHvl cells. Consistent with a role of the acetylcholine in 


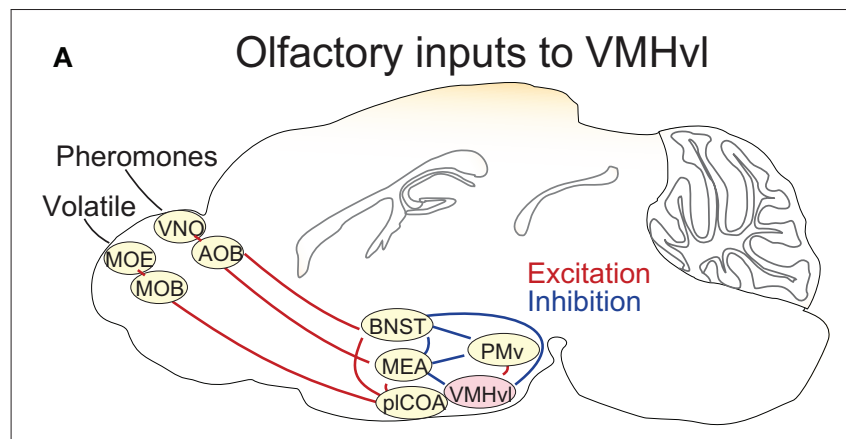

B Modulation of $\mathrm{VMHvl}$ baseline activity

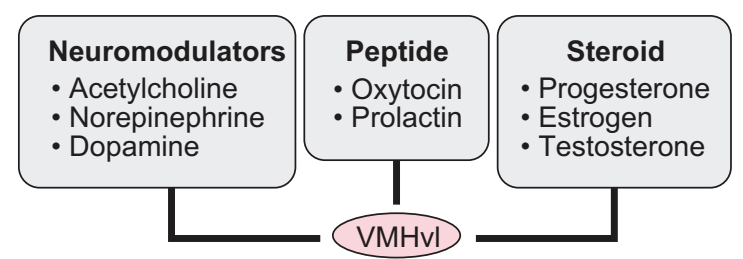

\section{c Generation of attack initiation signal}

\author{
Net input Local inhibitory: LHAjvv, TU \\ Distal inhibitory: MEA, BNST, LS \\ Distal excitatory: PMv, BMAp, PA, SUBv
}

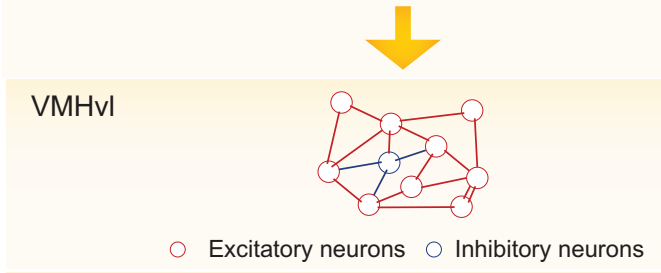

Net output

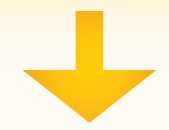

FIGURE 3 | Circuit mechanisms underlying VMHvl activity change during agonistic encounters. (A) The neural circuits upstream of the VMHvl that relay olfactory information. (B) Neuromodulators, neuropeptides, and neurosteroids that could potentially generate increased spontaneous activity in the VMHVI and cause sustained aggressive state. (C) Schematics illustrating a model responsible for activity increase at the VMHvl during attack initiation. In the model, inputs from the upstream regions bring the VMHvl activity to a threshold and then the recurrent excitatory network within the VMHvl quickly amplifies the signal to initiate attack and maintain it throughout the attack. OE, olfactory epithelium; VNO, vomeronasal organ; MOB, main olfactory bulb; AOB, accessory olfactory bulb; BNST, bed nucleus of stria terminalis; MEA, medial amygdala; plCOA, posterolateral cortical amygdala; PMv, ventral premammillary nucleus; VMHvl, ventromedial hypothalamus ventrolateral part. LHAjvv, lateral hypothalamic area, juxtaventromedial region, ventral zone; TU, tuberal nucleus; LS, lateral septum; BMAp, posterior basomedial nucleus; PA, posterior amygdala; SUBv, ventral subiculum.

enhancing VMH activity, microinjection of acetylcholine into the hypothalamus induces rage responses in cats, such as growling, hissing, and piloerection (Karmos-Varszegi and Karmos, 1977; Brudzynski, 1981; Siegel et al., 1999). Interestingly, the popular pharmacogenetics reagent, DREADD, is based upon muscarinic acetylcholine receptor, M3 (Dong et al., 2010). When DREADDq was virally expressed in the VMHvl PR+ cells, $\mathrm{CNO}$ (a selective ligand of DREADDs but see Gomez et al., 2017) mediated DREADDq activation significantly enhanced the probability and frequency of attacks in male mice, suggesting that the muscarinic activation in the VMHvl can potentially enhance aggressiveness of the animal.

Neuropeptides such as oxytocin, could also play a role in enhancing the spontaneous activity of the VMHvl. The oxytocin receptor is a Gq coupled receptor and expressed highly in the VMHvl (Young et al., 1997; Gould and Zingg, 2003) (www.brainmap.org, experimental ID: 75081001). In vitro slice recording showed that oxytocin can directly excite VMHvl cells when bath applied (Inenaga et al., 1991). The source of oxytocin to the $\mathrm{VMHvl}$ is not clear. Intriguingly, in situ hybridization revealed a cluster of OXT expressing cells lying along the ventral edge of the hypothalamus right against the VMHvl (www.brain-map.org, experiment ID: 112648396). Given that oxytocin can be released from not only axons but also dendrites (Ludwig, 1998), local oxytocin release from those ventrally situated oxytocinergic cells are likely to have strong influence on the adjacent cells in the VMHvl.

Estrogen is likely another potential contributor to alter spontaneous activity in VMHvl cells and it's actions can modulate activity on a variety of timescales. In the male brain, estrogen is believed to be synthesized by the action of the enzyme aromatase on testosterone (Ubuka and Tsutsui, 2014). Estrogen exerts its effect on cells through both slow genomic and fast membrane mechanisms. While the genomic actions of estrogen take hours for changes in protein expression to occur, nongenomic activation of estrogen occur within seconds to minutes through binding to the membrane estrogen receptor and kinase activation or calcium mobilization (Morley et al., 1992; Brubaker and Gay, 1999; Vasudevan and Pfaff, 2008). Given that the activity of aromatase can be regulated by phosphorylation within in seconds to minutes (Balthazart et al., 2001a,b), the local concentration of estrogen can rise rapidly and this can dynamically regulate the activity of cells that express membrane estrogen receptors on a similar timescale (Soma et al., 2004; Pradhan et al., 2010). The VMHvl is enriched with membrane estrogen receptor (Hazell et al., 2009) and patch clamp recording in slice preparation has shown that bath-applied estrogen can potentiate excitatory responses of VMHvl cells within $5 \mathrm{~min}$ (Kow et al., 2006). Behaviorally, estradiol supplements have also been shown to quickly enhance aggression. For example, orally administrated estradiol increases territorial aggression in male sparrow within $20 \mathrm{~min}$ (Heimovics et al., 2015), and subcutaneous administration of estradiol doubled male aggressive behavior within $15 \mathrm{~min}$ in two species of Peromyscus mice (Trainor et al., 2007, 2008).

While pharmacological studies, receptor expression patterns and in vitro recordings suggest that neuromodulatory mechanisms have the potential to change the VMHvl activity (Table 2), it remains unclear which mechanisms are utilized to facilitate VMHvl excitation under natural agonistic conditions. The development of genetically encoded protein sensors for 
TABLE 2 | Neuromodulation at the VMHvl.

\begin{tabular}{|c|c|c|c|c|c|}
\hline Region & Substrate & Subclass & Type & Neuralactivity & Reference \\
\hline & Oxytocin & - & $\mathrm{Gq}$ & $\uparrow$ & Inenaga et al., 1991 \\
\hline & Prolactin & - & Type I cytokine receptor family & $\uparrow$ & Moss et al., 1985 \\
\hline & Acetylcholine & $\alpha-7$ nicotinic & Nicotinic & $\uparrow$ & $\begin{array}{l}\text { Baddick and Marks, } \\
2011\end{array}$ \\
\hline & Acetylcholine & Ml,M3,M5 & $\mathrm{Gq}$ & $\uparrow$ & Levey, 1993 \\
\hline \multirow[t]{6}{*}{ VMHvl } & Acetylcholine & $\mathrm{M} 2, \mathrm{M} 4$ & $\mathrm{Gi}$ & $\downarrow$ & Levey, 1993 \\
\hline & Estrogen & Esr1 & Membranelocalized & $\uparrow$ & Kow et al., 2006 \\
\hline & $\mathrm{NE}$ & $\alpha 1 a$ & $\mathrm{Gq}$ & $\uparrow$ & Day et al., 1997 \\
\hline & $\mathrm{NE}$ & $\alpha 2 c$ & $\mathrm{Gi}$ & $\downarrow$ & Wang et al., 1996 \\
\hline & Dopamine & $\mathrm{D} 2$ & Gi & $\downarrow$ & Moss et al., 1985 \\
\hline & Serotonin & $5 \mathrm{HT} 1 \mathrm{~A}$ & Gi & $\downarrow$ & Wright et al., 1995 \\
\hline
\end{tabular}

A summary of receptors of neuromodulators, neurosteroids, and neuropeptides expressed in the VMHVI and their potential influences on the VMHVI activity.

biological compounds will be particularly useful in revealing the natural release of those compounds into the VMHvl (Kuner and Augustine, 2000; McLachlan et al., 2011; Marvin et al., 2013). Future studies that combine blocking or knocking down specific receptors and in vivo recording will be an effective way to reveal the contribution of a specific receptors to the increased activity of VMHvl cells during an aggressive state and to the behavior itself. The neuromodulators mentioned above are by no means complete, VMHvl expresses many other neuropeptide [cholecystokinin (Xu et al., 2012)] and hormone [e.g., progesterone (Furuta et al., 2010), androgen (Simerly et al., 1990; Mitra et al., 2003), prolactin (Chiu and Wise, 1994), glucocorticoid (Aronsson et al., 1988), and corticotropin-releasing hormone (Makino et al., 1998)] receptors and thus are likely under the influence of a cocktail of neurochemicals.

\section{Circuit Mechanisms for Increasing VMHvl Activity to Initiate Attack}

Optogenetic manipulations clearly demonstrate that increasing VMHvl activity can initiate attack (Lin et al., 2011; Lee et al., 2014). In addition, electrophysiological recording show that the VMHvl activity increases during attack and even starts to rise prior to attack onset (Falkner et al., 2014). What circuit mechanisms give rise to this excitatory response prior to and during attack under natural conditions? We speculate that it is the combined result of upstream inputs and local excitatory networks. The inputs to the VMHvl are diverse, coming from local cells in and surrounding the $\mathrm{VMHvl}$, other regions of the hypothalamus, and beyond. To complicate matters, the VMHvl receives far more inhibitory inputs than excitatory inputs. The $\mathrm{VMH}$ itself is densely glutamatergic and the number of intermingled inhibitory neurons is extremely small. However, several regions surrounding the VMHvl, including the lateral hypothalamus, juxtaventromedial region, ventral zone (LHAjvv), and the tuberal nucleus (TU), are enriched of GABAergic cells and may provide direct inhibitory drive (Canteras et al., 1994) (For distribution of GABAergic cells: www.brain-map.org experiment 72081554; Glutamatergic cells: experiment 73818754). Tracing studies have revealed dense projections from the $\mathrm{VMH}$ surrounding regions to the $\mathrm{VMH}$, suggesting a strong local control of the VMHvl activity by its surrounding zones (Canteras et al., 1994; Hahn and Swanson, 2015). Besides sources of local inhibition, antegrade tracing studies suggested that the VMHvl also receives strong inputs from the MEA (Canteras et al., 1995), BNST (Dong and Swanson, 2004), lateral septum (LS) (Risold and Swanson, 1997), and medial preoptic area (MPOA) (Simerly and Swanson, 1988), all of which contain mainly or nearly exclusively GABAergic cells. In support of a role for these inhibitory inputs in aggression, optogenetic activation of the MEA GABAergic cells elicits immediate attack, suggesting that the attack could be initiated upstream of the VMHvl although it is unclear whether the MEA activation induced attack is through its direct projection to the VMHvl or not (Hong et al., 2014; Padilla et al., 2016). In comparison to brain-wide sources of inhibitory inputs, excitatory inputs to the VMHvl are less studied. They include inputs from the ventral premammlinary nucleus (PMv) (Canteras et al., 1992a), the basomedial amygdala posterior part (BMAp) (Petrovich et al., 1996), posterior amygdala (PA) (Canteras et al., 1992b), and ventral subiculum (SUBv) (Canteras and Swanson, 1992; Tang et al., 2016). The roles of those glutamatergic regions in aggressive behaviors remain largely unclear.

Within the VMHvl, given that over $95 \%$ cells are glutamatergic (Choi et al., 2005) and these cells form numerous synaptic contacts with each other (Nishizuka and Pfaff, 1989), it contains the proper synaptic substrates to support recurrent synaptic excitation. Thus, we speculate that VMHvl cells may integrate inputs from the upstream regions until a "threshold" is reached and then the local recurrent VMHvl network may quickly amplify the activity to initiate attack and maintain this activity throughout the attack (Douglas et al., 1995; Schurger et al., 2012) (Figure 3C). Increases in the spontaneous activity in the VMHvl will help bring the activity closer to the "threshold" and thus increase the probability of the "threshold-crossing" event. In support of this hypothesis, pharmacogenetically increasing the spontaneous activity of the VMHvl cells significantly increases the frequency of attacks although it does not initiate attack immediately (Yang et al., 2017) while decreasing the spontaneous 
activity of the VMHvl reduces the frequency of attack (Lin et al., 2011; Falkner et al., 2016).

\section{THE INFLUENCE OF THE VMHVL ON CIRCUITS FOR SOCIAL PERCEPTION AND ACTION}

\section{Aggressive State and Perception of an Opponent}

The motivational state of an animal influences the perception of relevant sensory stimuli. For example, the hunger state influences the attractiveness of food whereas the sexual arousal state influences the appeal of a potential mate. During subthreshold electric stimulation of hypothalamic attack area, it was noted that stimulation seems to" promote a shift from friendly social contact toward a more apprehensive and touchy social attitude" (Kruk, 2014). The neural mechanisms responsible for the perceptual change with the motivational state remain largely unknown. Recently, an elegant study by Livneh et al. showed that the responses of insular cortex to food reward are significantly modulated by the hunger state of the animal (Livneh et al., 2017) (Figure 4). While insular cortical neurons strongly responded to food in starved mice, the responses are virtually abolished under satiety. Importantly, activity of the AGRP neurons was found casually linked to the change in responses of insular cortical neurons: artificial activation of the AGRP neurons largely restored the responses of insular cortical neurons to food in satiated mice (Livneh et al., 2017). Detailed circuit mapping revealed that AGRP neurons project to the insular cortex through paraventricular thalamus (PVT) and basomedial amygdala (BMA). Taken together, this study revealed a potential circuit through which the motivational signal encoded in the subcortical region affects the perceptual responses in the cortex.

Intriguingly, PVT also receives strong inputs from the VMHvl. In fact, PVT is the only thalamic region to which the VMHvl projects (Canteras et al., 1994). In addition to the VMHvl and arcuate nucleus, PVT also receives inputs from a wide range of hypothalamic structures, including the dorsomedial, suprachiasmatic, paraventricular, suprachiasmatic nuclei as well as the preoptic, anterior, zona incerta, and lateral hypothalamic areas (Cornwall and Phillipson, 1988; Chen and Su, 1990; Kirouac, 2015). Thus, it is possible that PVT represents a common gateway through which the motivational and physiological signals encoded in the subcortical areas influence the perceptual processing in the cortex (Figure 4). During a heightened aggressive state, activity in VMHvl may excite the PVT neurons and influence the evaluation process of a potential opponent in the cortex. The influences of the PVT onto the cortex could be through the BMA as shown in Livneh et al. (2017) or via a direct projection to the prefrontal cortex (PFC) (Berendse and Groenewegen, 1991; Moga et al., 1995; Kirouac, 2015). Recent studies revealed that the neural activity in the PFC influences the dominance behaviors of an animal (Wang et al., 2011; Zhou et al., 2017). In a test that involves two male mice encountering each other in a narrow tube, the PFC activated animals are more likely to push the opponent while

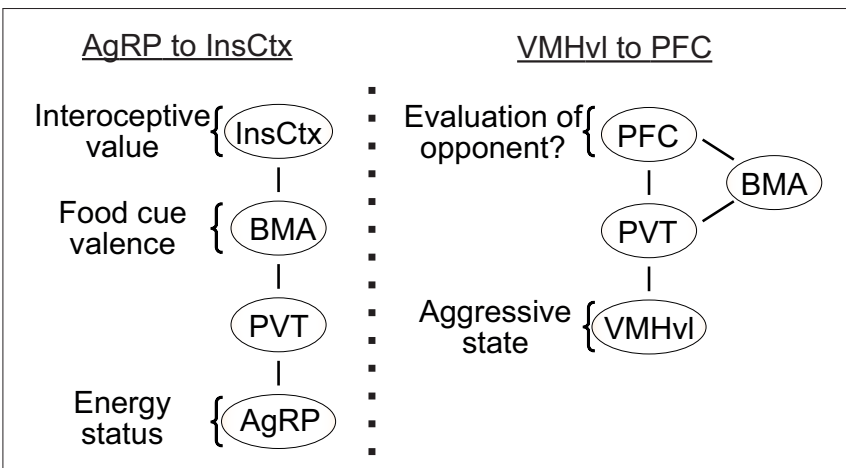

FIGURE 4 | The potential pathways for "bottom up" modulation. (Left) the key relays to transfer hunger state related information from AGRP neurons to the insular cortex; (Right) a putative pathway that transfers aggressive state related information from the VMHvl to the prefrontal cortex. InsCox, insular cortex; BMA, basomedial amygdala; PVT, paraventricular nucleus of thalamus; AgRP, agouti-related peptide in the arcuate nucleus; PFC, prefrontal cortex; $\mathrm{VMHvl}$, ventromedial hypothalamus ventrolateral part.

the PFC inactivated animals are more likely to retreat (Zhou et al., 2017). In a warm-spot test, PFC activated animals occupied the warm spot in a cold arena for a significantly longer time in comparison to control animals (Zhou et al., 2017). Given that dominance behavior depends critically on evaluating self and opponent, changes in dominance behavior may reflect changes in perceived relationship of an opponent to oneself. Indeed, human fMRI studies revealed high activity in the medial PFC in a self-referencing task that requires the subject to compare oneself and others (Amodio and Frith, 2006; Mitchell et al., 2006). Taken together, we hypothesize that the PFC may represent a critical site for evaluation of an opponent in reference to self and a heightened aggressive state modulated from ongoing VMHvl activity may influence the activity of PFC through its projection to PVT and bias the evaluation process. Future studies that simultaneously manipulate the hypothalamic activity and monitor the cortical cell activity could be a general and fruitful strategy to understand the neural mechanisms underlying the motivational modulation of social perception.

\section{Influences of the VMHvl on Midbrain Structures during Attack}

The attack initiation signal in the VMHvl ultimately needs to activate premotor areas to drive the motor execution of attack. Among all the downstream regions of the VMHvl, the periaqueductal gray (PAG) represents the most likely relay between the VMHvl and the motor neurons in the spinal cord. PAG is a midbrain structure located around the cerebral aqueduct. PAG neurons project to the nucleus raphe magnus (NRM) and pallidus (NRP), the ventral part of the caudal pontine, the medullary reticular formation (Abols and Basbaum, 1981; Holstege, 1988; Mouton and Holstege, 1994; Cameron et al., 1995), which in turn project diffusely, but very strongly to all parts of the gray matter throughout the length of the spinal cord (Kuypers and Maisky, 1975; Tohyama et al., 1979; Holstege and Kuypers, 1982). The strength of this projection from the VMHvl to PAG has long been recognized (Beart et al., 1988; 
Chung et al., 1990; Canteras et al., 1994). A survey of the Allan brain atlas (www.brain-map.org) illustrated the exceedingly high strength of this projection: in the list ranking the tracing results according to the largest terminal fields produced within the PAG, the $\mathrm{VMH}$ appeared in 6 of the 10 topmost positions. The 4 other top positions were occupied by areas adjacent to the $\mathrm{VMH}$, such as the tubular- and the lateral hypothalamic area, which all receive strong inputs from the VMHvl. Thus, VMHvl projections to the PAG, either directly or indirectly, are likely to have strong impact on the PAG cell activity.

It is important to note that PAG is a massive and complex structure. In mice, it spans nearly $2.5 \mathrm{~mm}$ along the A-P axis (or $\sim 25 \%$ of the entire mouse brain) and is composed of multiple columns surrounding the midbrain aqueduct (dorsal, dorsolateral, lateral, ventrolateral, and ventral) (Bandler and Shipley, 1994; Bandler et al., 2000). Not surprisingly, PAG has been indicated in many social and non-social functions including defense, predation, lordosis, vocalization, nociception, analgesia, and cardiovascular control (Bandler and Shipley, 1994; Behbehani, 1995; Wang et al., 2015; Han et al., 2017; Motta et al., 2017). Due to the involvement of PAG in multiple behaviors, direct electric stimulation of the PAG has only been shown to induce attack with motor disturbance (Mos et al., 1982). More frequently, reports of direct PAG stimulation have elicited robust defense related motor patterns, including immobility, flight and escape jump (Bandler et al., 2000), though these studies do not rule out direct involvement of the PAG in attack initiation. Future studies that identify the molecular identities of the PAG cells that are relevant for aggression will be an essential step for understanding how VMHvl inputs influence PAG cells during aggression.

In addition to the PAG, there likely exist parallel pathways to generate attack, given that a large lesion that destroyed the entire PAG at one level only transiently impaired aggressive behaviors (Mos et al., 1983). The other midbrain region that has been recently implicated in aggression is the ventral tegmental area (VTA): optogenetic activation of the dopaminergic cells increased the time spent attacking male and female intruders ( $\mathrm{Yu}$ et al., 2014). Microdialysis showed that the dopamine level in the nucleus accumbens (NA) increases when the animal anticipates attack and after attack although its release during the moment of attack remains unknown due to the low temporal sensitivity of microdialysis (Ferrari et al., 2003). D1 and D2 receptor antagonists effectively reduce attack and aggression seeking in mice (Nelson and Trainor, 2007; Couppis and Kennedy, 2008). In fact, D2 receptor antagonist risperidone is a commonly used drug to reduce aggressive behavior in patients with autism and schizophrenia (Soyka et al., 2007; Bronsard et al., 2010). Although the VMHvl and dopamine system are clearly both activated during aggression, they have been studied largely independently

\section{REFERENCES}

Abols, I. A., and Basbaum, A. I. (1981). Afferent connections of the rostral medulla of the cat: a neural substrate for midbrain-medullary interactions in the modulation of pain. J. Comp. Neurol. 201, 285-297. doi: 10.1002/cne.9020 10211 and the relationship between these two regions remain unclear. The VMHvl appears to project sparsely if at all to the VTA and vice versa (Canteras et al., 1994). However, the VMHvl does project densely to the MPOA which in turn projects to the VTA moderately (Simerly and Swanson, 1988; Canteras et al., 1994). The MPOA-VTA-NA pathway has been hypothesized as a key route for transferring the motivational signal in the hypothalamus to the striatal motor system to guide goal directed behaviors. Future circuit dissection studies will help elucidate the relevance of the VMHvl-MPOA-VTA-NA circuit in mediating aggressive behaviors.

\section{CONCLUDING MARKS}

After decades of relative quiescence, aggression research has regained its momentum. Recent studies using genetically precise, cell-type specific manipulation, tracing, and in vivo recording have quickly advanced our knowledge regarding the neural substrates relevant for aggression. Beyond the VMHvl and associated regions mentioned above, including the MEA (Hong et al., 2014), PMv (Motta et al., 2013), and VTA (Yu et al., 2014), aggression has also been shown to be modulated by GABAergic neurons in lateral habenula (Golden et al., 2016), serotonin cells in dorsal raphe (Niederkofler et al., 2016), GABAergic neurons in lateral septum (Wong et al., 2016), and pyramidal cells in prefrontal cortex (Takahashi et al., 2014). Although neural populations that can alter aggressive behaviors are being continuously discovered, efforts to understand the endogenous responses of the cells under natural behaviors remain limited. To date, the $\mathrm{VMHvl}$ remains the only region from which the electrophysiological responses during aggressive behaviors have been extensively studied. Such information is essential for interpreting the behavioral changes caused by the manipulation and understanding the role of these cells in the whole-brain aggression circuit. By combining physiology with connectivity, causality and correlation studies, we hope that a comprehensive and integrated aggression circuit will finally emerge.

\section{AUTHOR CONTRIBUTIONS}

$\mathrm{DL}$ wrote the manuscript. $\mathrm{YH}$ and $\mathrm{KH}$ made the figures. $\mathrm{KH}$ commented and AF edited the manuscript.

\section{FUNDING}

This research was supported 1R01MH101377 (NIMH) (DL), 1R21MH105774-01A1 (NIMH) (DL), Mathers foundation (DL), Irma T. Hirschl Career Scientist Award (DL), Uehara postdoctoral fellowship (KH), and K99MH109674 (AF).

Amodio, D. M., and Frith, C. D. (2006). Meeting of minds: the medial frontal cortex and social cognition. Nat. Rev. Neurosci. 7, 268-277. doi: $10.1038 / \mathrm{nrn} 1884$

Aponte, Y., Atasoy, D., and Sternson, S. M. (2011). AGRP neurons are sufficient to orchestrate feeding behavior rapidly and without training. Nat. Neurosci. 14, 351-355. doi: 10.1038/nn.2739 
Aronsson, M., Fuxe, K., Dong, Y., Agnati, L. F., Okret, S., and Gustafsson, J. A. (1988). Localization of glucocorticoid receptor mRNA in the male rat brain by in situ hybridization. Proc. Natl. Acad. Sci. U.S.A. 85, 9331-9335. doi: $10.1073 /$ pnas.85.23.9331

Baddick, C. G., and Marks, M. J. (2011). An autoradiographic survey of mouse brain nicotinic acetylcholine receptors defined by null mutants. Biochem. Pharmacol. 82, 828-841. doi: 10.1016/j.bcp.2011.04.019

Balthazart, J., Baillien, M., and Ball, G. F. (2001a). Rapid and reversible inhibition of brain aromatase activity. J. Neuroendocrinol. 13, 63-73. doi: 10.1046/j.1365-2826.2001.00598.x

Balthazart, J., Baillien, M., and Ball, G. F. (2001b). Phosphorylation processes mediate rapid changes of brain aromatase activity. J. Steroid Biochem. Mol. Biol. 79, 261-277. doi: 10.1016/S0960-0760(01)00143-1

Bandler, R., and Shipley, M. T. (1994). Columnar organization in the midbrain periaqueductal gray: modules for emotional expression? Trends Neurosci. 17, 379-389. doi: 10.1016/0166-2236(94)90047-7

Bandler, R., Keay, K. A., Floyd, N., and Price, J. (2000). Central circuits mediating patterned autonomic activity during active vs. passive emotional coping. Brain Res. Bull. 53, 95-104. doi: 10.1016/S0361-9230(00)00313-0

Beart, P. M., Nicolopoulos, L. S., West, D. C., and Headley, P. M. (1988). An excitatory amino acid projection from ventromedial hypothalamus to periaqueductal gray in the rat: autoradiographic and electrophysiological evidence. Neurosci. Lett. 85, 205-211. doi: 10.1016/0304-3940(88)90352-7

Behbehani, M. M. (1995). Functional characteristics of the midbrain periaqueductal gray. Prog. Neurobiol. 46, 575-605.

Berendse, H. W., and Groenewegen, H. J. (1991). Restricted cortical termination fields of the midline and intralaminar thalamic nuclei in the rat. Neuroscience 42, 73-102. doi: 10.1016/0306-4522(91)90151-D

Betley, J. N., Xu, S., Z.,Cao, F. H., Gong, R., Magnus, C. J., and Sternson, S. M. (2015). Neurons for hunger and thirst transmit a negative-valence teaching signal. Nature 521, 180-185. doi: 10.1038/nature 14416

Bouthenet, M. L., Souil, E., Martres, M. P., Sokoloff, P., Giros, B., and Schwartz, J. C. (1991). Localization of dopamine D3 receptor mRNA in the rat brain using in situ hybridization histochemistry: comparison with dopamine D2 receptor mRNA. Brain Res. 564, 203-219. doi: 10.1016/0006-8993(91) 91456-B

Bronsard, G., Botbol, M., and Tordjman, S. (2010). Aggression in low functioning children and adolescents with autistic disorder. PLOS ONE 5:e14358. doi: 10.1371/journal.pone.0014358

Brubaker, K. D., and Gay, C. V. (1999). Estrogen stimulates protein tyrosine phosphorylation and Src kinase activity in avian osteoclasts. J. Cell. Biochem. 76, 206-216. doi: 10.1002/(SICI)1097-4644(20000201)76:2<206::AID-JCB5>3.0.CO;2-R

Brudzynski, S. M. (1981). Carbachol-induced agonistic behavior in cats: aggressive or defensive response. Acta Neurobiol. Exp. 41, 15-32.

Cameron, A. A., Khan, I. A., Westlund, K. N., Cliffer, K. D., and Willis, W. D. (1995). The efferent projections of the periaqueductal gray in the rat: a Phaseolus vulgaris-leucoagglutinin study. I. Ascending projections. J. Comp. Neurol. 351, 568-584. doi: 10.1002/cne.903510407

Canteras, N. S., and Swanson, L. W. (1992). Projections of the ventral subiculum to the amygdala, septum, and hypothalamus: a PHAL anterograde tract-tracing study in the rat. J. Comp. Neurol. 324, 180-194. doi: 10.1002/cne.903240204

Canteras, N. S., Simerly, R. B., and Swanson, L. W. (1992a). Projections of the ventral premammillary nucleus. J. Comp. Neurol. 324, 195-212. doi: 10.1002/cne. 903240205

Canteras, N. S., Simerly, R. B., and Swanson, L. W. (1992b). Connections of the posterior nucleus of the amygdala. J. Comp. Neurol. 324, 143-179. doi: $10.1002 / \mathrm{cne} .903240203$

Canteras, N. S., Simerly, R. B., and Swanson, L. W. (1994). Organization of projections from the ventromedial nucleus of the hypothalamus: a Phaseolus vulgaris-leucoagglutinin study in the rat. J. Comp. Neurol. 348, 41-79. doi: $10.1002 /$ cne. 903480103

Canteras, N. S., Simerly, R. B., and Swanson, L. W. (1995). Organization of projections from the medial nucleus of the amygdala: a PHAL study in the rat. J. Comp. Neurol. 360, 213-245. doi: 10.1002/cne.903600203

Chamero, P., Marton, T. F., Logan, D. W., Flanagan, K., Cruz, J. R., Saghatelian, A., et al. (2007). Identification of protein pheromones that promote aggressive behaviour. Nature 450, 899-902. doi: 10.1038/nature05997
Chen, S., and Su, H. S. (1990). Afferent connections of the thalamic paraventricular and parataenial nuclei in the rat-a retrograde tracing study with iontophoretic application of Fluoro-Gold. Brain Res. 522, 1-6. doi: 10.1016/0006-8993(90)91570-7

Chen, Y., Lin, Y. C., Kuo, T. W., and Knight, Z. A. (2015). Sensory detection of food rapidly modulates arcuate feeding circuits. Cell 160, 829-841. doi: $10.1016 /$ j.cell.2015.01.033

Cherek, D. R., Thompson, T., and Heistad, G. T. (1973). Responding maintained by the opportunity to attack during an interval food reinforcement schedule. $J$. Exp. Anal. Behav. 19, 113-123. doi: 10.1901/jeab.1973.19-113

Chiu, S., and Wise, P. M. (1994). Prolactin receptor mRNA localization in the hypothalamus by in situ hybridization. J. Neuroendocrinol. 6, 191-199. doi: 10.1111/j.1365-2826.1994.tb00572.x

Choi, G. B., Dong, H. W., Murphy, A. J., Valenzuela, D. M., Yancopoulos, G. D., Swanson, L. W., et al. (2005). Lhx6 delineates a pathway mediating innate reproductive behaviors from the amygdala to the hypothalamus. Neuron 46, 647-660. doi: 10.1016/j.neuron.2005.04.011

Chung, S. K., Pfaff, D. W., and Cohen, R. S. (1990). Projections of ventromedial hypothalamic neurons to the midbrain central gray: an ultrastructural study. Neuroscience 38, 395-407. doi: 10.1016/0306-4522(90)90037-5

Clarke, P. B., Schwartz, R. D., Paul, S. M., Pert, C. B., and Pert, A. (1985). Nicotinic binding in rat brain: autoradiographic comparison of [3H]acetylcholine, [3H]nicotine, and [125I]-alpha-bungarotoxin. J. Neurosci. 5, 1307-1315.

Cornwall, J., and Phillipson, O. T. (1988). Afferent projections to the dorsal thalamus of the rat as shown by retrograde lectin transport-I. The mediodorsal nucleus. Neuroscience 24, 1035-1049. doi: 10.1016/0306-4522(88)90085-1

Couppis, M. H., and Kennedy, C. H. (2008). The rewarding effect of aggression is reduced by nucleus accumbens dopamine receptor antagonism in mice. Psychopharmacology 197, 449-456. doi: 10.1007/s00213-007-1054-y

Day, H. E., Campeau, S., Watson, S. J. Jr., and Akil, H. (1997). Distribution of alpha 1a-, alpha $1 \mathrm{~b}$ - and alpha 1d-adrenergic receptor mRNA in the rat brain and spinal cord. J. Chem. Neuroanat. 13, 115-139. doi: 10.1016/S0891-0618(97)00042-2

Donato, J. Jr., Cavalcante, J. C., Silva, R. J., Teixeira, A. S., Bittencourt, J. C., and Elias, C. F. (2010). Male and female odors induce Fos expression in chemically defined neuronal population. Physiol. Behav. 99, 67-77. doi: 10.1016/j.physbeh.2009.10.012

Dong, H. W., and Swanson, L. W. (2004). Projections from bed nuclei of the stria terminalis, posterior division: implications for cerebral hemisphere regulation of defensive and reproductive behaviors. J. Comp. Neurol. 471, 396-433. doi: $10.1002 /$ cne.20002

Dong, S., Rogan, S. C., and Roth, B. L. (2010). Directed molecular evolution of DREADDs: a generic approach to creating next-generation RASSLs. Nat. Protoc. 5, 561-573. doi: 10.1038/nprot.2009.239

Douglas, R. J., Koch, C., Mahowald, M., Martin, K. A., and Suarez, H. H. (1995). Recurrent excitation in neocortical circuits. Science 269, 981-985. doi: $10.1126 /$ science. 7638624

Dulac, C., and Torello, A. T. (2003). Molecular detection of pheromone signals in mammals: from genes to behaviour. Nat. Rev. Neurosci. 4, 551-562. doi: $10.1038 / \mathrm{nrn} 1140$

Egorov, A. V., Hamam, B. N., Fransén, E., Hasselmo, M. E., and Alonso, A. A. (2002). Graded persistent activity in entorhinal cortex neurons. Nature 420, 173-178. doi: 10.1038/nature01171

Falkner, A. L., Dollar, P., Perona, P., Anderson, D. J., and Lin, D. (2014). Decoding ventromedial hypothalamic neural activity during male mouse aggression. J. Neurosci. 34, 5971-5984. doi: 10.1523/JNEUROSCI.5109-13.2014

Falkner, A. L., Grosenick, L., Davidson, T. J., Deisseroth, K., and Lin, D. (2016). Hypothalamic control of male aggression-seeking behavior. Nat. Neurosci. 19, 596-604. doi: 10.1038/nn.4264

Ferrari, P. F., van Erp, A. M., Tornatzky, W., and Miczek, K. A. (2003). Accumbal dopamine and serotonin in anticipation of the next aggressive episode in rats. Eur. J. Neurosci. 17, 371-378. doi: 10.1046/j.1460-9568.2003.02447.x

Fish, E. W., De Bold, J. F., and Miczek, K. A. (2002). Aggressive behavior as a reinforcer in mice: activation by allopregnanolone. Psychopharmacology 163, 459-466. doi: 10.1007/s00213-002-1211-2

Fish, E. W., DeBold, J. F., and Miczek, K. A. (2005). Escalated aggression as a reward: corticosterone and $\mathrm{GABA}(\mathrm{A})$ receptor positive modulators in mice. Psychopharmacology 182, 116-127. doi: 10.1007/s00213-005-0064-x 
Furuta, M., Fukushima, A., Chiba, S., Sano, A., Akema, T., Kimura, F., et al. (2010). Progesterone receptor immunoreactivity in the brains of ovariectomized aged rats., Neuroreport 21, 777-781. doi: 10.1097/WNR.0b013e32833c5b6f

Golden, S. A., Heins, C., Venniro, M., Caprioli, D., Zhang, M., Epstein, D. H., et al. (2017). Compulsive addiction-like aggressive behavior in mice. Biol. Psychiatry 82, 239-248. doi: 10.1016/j.biopsych.2017.03.004

Golden, S. A., Heshmati, M., Flanigan, M., Christoffel, D. J., Guise, K., Pfau, M. L., et al. (2016). Basal forebrain projections to the lateral habenula modulate aggression reward. Nature 534, 688-692. doi: 10.1038/nature18601

Gomez, J. L., Bonaventura, J., Lesniak, W., Mathews, W. B., Sysa-Shah, P., Rodriguez, L. A., et al. (2017). Chemogenetics revealed: DREADD occupancy and activation via converted clozapine. Science 357, 503-507. doi: 10.1126/science.aan2475

Gould, B. R., and Zingg, H. H. (2003). Mapping oxytocin receptor gene expression in the mouse brain and mammary gland using an oxytocin receptor-LacZ reporter mouse. Neuroscience 122, 155-167. doi: 10.1016/S0306-4522(03)00283-5

Hahn, J. D., and Swanson, L. W. (2015). Connections of the juxtaventromedial region of the lateral hypothalamic area in the male rat. Front. Syst. Neurosci. 9:66. doi: 10.3389/fnsys.2015.00066

Halasz, J., Liposits, Z., Meelis, W., Kruk, M. R., and Haller, J. (2002). Hypothalamic attack area-mediated activation of the forebrain in aggression. Neuroreport 13, 1267-1270. doi: 10.1097/00001756-200207190-00010

Han, W., Tellez, L. A., Rangel, M. J. Jr., Motta, S. C., Zhang, X., Perez, I. O., et al. (2017). Integrated control of predatory hunting by the central nucleus of the amygdala. Cell 168, 311 e18-324 e18. doi: 10.1016/j.cell.2016.12.027

Hashikawa, K., Hashikawa, Y., Falkner, A., and Lin, D. (2016). The neural circuits of mating and fighting in male mice. Curr. Opin. Neurobiol. 38, 27-37. doi: 10.1016/j.conb.2016.01.006

Hashikawa, K., Hashikawa, Y., Tremblay, R., Zhang, J., Feng, J. E., Sabol, A., et al. (2017). Esr1+ cells in the ventromedial hypothalamus control female aggression. Nat. Neurosci. 20, 1580-1590. doi: 10.1038/nn.4644

Hazell, G. G., Yao, S. T., Roper, J. A., Prossnitz, E. R., O’Carroll, A. M., and Lolait, S. J. (2009). Localisation of GPR30, a novel G protein-coupled oestrogen receptor, suggests multiple functions in rodent brain and peripheral tissues. J. Endocrinol. 202, 223-236. doi: 10.1677/JOE-09-0066

Heimovics, S. A., Ferris, J. K., and Soma, K. K. (2015). Non-invasive administration of 17 beta-estradiol rapidly increases aggressive behavior in non-breeding, but not breeding, male song sparrows. Horm. Behav. 69, 31-38. doi: 10.1016/j.yhbeh.2014.11.012

Holstege, G. (1988). Direct and indirect pathways to lamina I in the medulla oblongata and spinal cord of the cat. Prog. Brain Res. 77, 47-94. doi: 10.1016/S0079-6123(08)62778-8

Holstege, G., and Kuypers, H. G. (1982). The anatomy of brain stem pathways to the spinal cord in cat. A labeled amino acid tracing study. Prog. Brain Res. 57, 145-175. doi: 10.1016/S0079-6123(08)64128-X

Hong, W., Kim, D. W., and Anderson, D. J. (2014). Antagonistic control of social versus repetitive self-grooming behaviors by separable amygdala neuronal subsets. Cell 158, 1348-1361. doi: 10.1016/j.cell.2014.07.049

Horio, T., Shimura, T., Hanada, M., and Shimokochi, M. (1986). Multiple unit activities recorded from the medial preoptic area during copulatory behavior in freely moving male rats. Neurosci. Res. 3, 311-320. doi: 10.1016/0168-0102(86)90023-4

Inenaga, K., Karman, H., Yamashita, H., Tribollet, E., Raggenbass, M., and Dreifuss, J. J. (1991). Oxytocin excites neurons located in the ventromedial nucleus of the Guinea-pig hypothalamus. J. Neuroendocrinol. 3, 569-573. doi: 10.1111/j.1365-2826.1991.tb00318.x

Jiang-Xie, L. F., Liao, H. M., Chen, C. H., Chen, Y. T., Ho, S. Y., Lu, D. H., et al. (2014). Autism-associated gene Dlgap2 mutant mice demonstrate exacerbated aggressive behaviors and orbitofrontal cortex deficits. Mol. Autism 5:32. doi: 10.1186/2040-2392-5-32

Kang, N., Baum, M. J., and Cherry, J. A. (2009). A direct main olfactory bulb projection to the 'vomeronasal' amygdala in female mice selectively responds to volatile pheromones from males. Eur. J. Neurosci. 29, 624-634. doi: 10.1111/j.1460-9568.2009.06638.x

Kang, N., Baum, M. J., and Cherry, J. A. (2011). Different profiles of main and accessory olfactory bulb mitral/tufted cell projections revealed in mice using an anterograde tracer and a whole-mount, flattened cortex preparation. Chem. Senses 36, 251-260. doi: 10.1093/chemse/bjq120

Kanne, S. M., and Mazurek, M. O. (2011). Aggression in children and adolescents with ASD: prevalence and risk factors. J. Autism Dev. Disord. 41, 926-937. doi: 10.1007/s10803-010-1118-4

Karmos-Várszegi, M., and Karmos, G. (1977). A comparative study of autonomic, somatic and bioelectric correlates of emotional reactions elicited by cholinergic stimulation of the hypothalamus and the ventral tegmentum [proceedings]. Act. Nerv. Super. 19, 123-124.

Kirouac, G. J. (2015). Placing the paraventricular nucleus of the thalamus within the brain circuits that control behavior. Neurosci. Biobehav. Rev. 56 315-329. doi: 10.1016/j.neubiorev.2015.08.005

Kollack-Walker, S., Watson, S. J., and Akil, H. (1997). Social stress in hamsters: defeat activates specific neurocircuits within the brain. J. Neurosci. 17, 8842-8855.

Kow, L. M., and Pfaff, D. W. (1985). Estrogen effects on neuronal responsiveness to electrical and neurotransmitter stimulation: an in vitro study on the ventromedial nucleus of the hypothalamus. Brain Res. 347, 1-10. doi: 10.1016/0006-8993(85)90883-2

Kow, L. M., Devidze, N., Pataky, S., Shibuya, I., and Pfaff, D. W. (2006). Acute estradiol application increases inward and decreases outward whole-cell currents of neurons in rat hypothalamic ventromedial nucleus. Brain Res. 1116, 1-11. doi: 10.1016/j.brainres.2006.07.104

Krashes, M. J., Koda, S., Ye, C., Rogan, S. C., Adams, A. C., Cusher, D. S., et al. (2011). Rapid, reversible activation of AgRP neurons drives feeding behavior in mice. J. Clin. Invest. 121, 1424-1428. doi: 10.1172/JCI46229

Kruk, M. R. (2014). Hypothalamic attack: a wonderful artifact or a useful perspective on escalation and pathology in aggression? a viewpoint. Curr. Top. Behav. Neurosci. 17, 143-188. doi: 10.1007/7854_2014_313

Kruk, M. R., van der Poel, A. M., and de Vos-Frerichs, T. P. (1979). The induction of aggressive behaviour by electrical stimulation in the hypothalamus of male rats. Behaviour 70, 292-322. doi: 10.1163/156853979X00106

Kruk, M. R., Vanderpoel, A. M., Meelis, W., Hermans, J., Mostert, P. G., Mos, J., et al. (1983). Discriminant-analysis of the localization of aggression-inducing electrode placements in the hypothalamus of male-rats. Brain Res. 260, 61-79. doi: 10.1016/0006-8993(83)90764-3

Kuner, T., and Augustine, G. J. (2000). A genetically encoded ratiometric indicator for chloride: capturing chloride transients in cultured hippocampal neurons. Neuron 27, 447-459. doi: 10.1016/S0896-6273(00)00056-8

Kuypers, H. G., and Maisky, V. A. (1975). Retrograde axonal transport of horseradish peroxidase from spinal cord to brain stem cell groups in the cat. Neurosci. Lett. 1, 9-14. doi: 10.1016/0304-3940(75)90004-X

Lammers, J. H., Kruk, M. R., Meelis, W., and van der Poel, A. M. (1988). Hypothalamic substrates for brain stimulation-induced attack, teethchattering and social grooming in the rat. Brain Res. 449 311-327. doi: 10.1016/0006-8993(88)91046-3

Lee, H., Kim, D. W., Remedios, R., Anthony, T. E., Chang, A., Madisen, L., et al. (2014). Scalable control of mounting and attack by Esr1+ neurons in the ventromedial hypothalamus. Nature 509, 627-632. doi: 10.1038/nature13169

Levey, A. I. (1993). Immunological localization of m1-m5 muscarinic acetylcholine receptors in peripheral tissues and brain. Life Sci. 52, 441-448. doi: 10.1016/0024-3205(93)90300-R

Levey, A. I., Edmunds, S. M., Heilman, C. J., Desmond, T. J., and Frey, K. A. (1994). Localization of muscarinic $\mathrm{m} 3$ receptor protein and $\mathrm{M} 3$ receptor binding in rat brain. Neuroscience 63, 207-221. doi: 10.1016/0306-4522(94)90017-5

Lin, D., Boyle, M. P., Dollar, P., Lee, H., Lein, E. S., Perona, P., et al. (2011). Functional identification of an aggression locus in the mouse hypothalamus. Nature 470, 221-226. doi: 10.1038/nature09736

Lipp, H. P., and Hunsperger, R. W. (1978). Threat, attack and flight elicited by electrical stimulation of the ventromedial hypothalamus of the marmoset monkey Callithrix jacchus. Brain Behav. Evol. 15, 260-293. doi: $10.1159 / 000123782$

Livneh, Y., Ramesh, R. N., Burgess, C. R., Levandowski, K. M., Madara, J. C., Fenselau, H., et al. (2017). Homeostatic circuits selectively gate food cue responses in insular cortex. Nature 546, 611-616. doi: 10.1038/nature22375

Ludwig, M. (1998). Dendritic release of vasopressin and oxytocin. J. Neuroendocrinol. 10, 881-895. 
Makino, S., Nishiyama, M., Asaba, K., Gold, P. W., and Hashimoto, K. (1998). Altered expression of type 2 CRH receptor mRNA in the VMH by glucocorticoids and starvation. Am. J. Physiol. 275, R1138-R1145.

Martínez, M., Guillén-Salazar, F., Salvador, A., and Simón, V. M. (1995). Successful intermale aggression and conditioned place preference in mice. Physiol. Behav. 58, 323-328. doi: 10.1016/0031-9384(95)00061-M

Marvin, J. S., Borghuis, B. G., Tian, L., Cichon, J., Harnett, M. T., Akerboom, J., et al. (2013). An optimized fluorescent probe for visualizing glutamate neurotransmission. Nat. Methods 10, 162-170. doi: 10.1038/nmeth.2333

May, M. E., and Kennedy, C. H. (2009). Aggression as positive reinforcement in mice under various ratio- and time-based reinforcement schedules. J. Exp. Anal. Behav. 91, 185-196. doi: 10.1901/jeab.2009.91-185

McLachlan, M. J., Katzenellenbogen, J. A., and Zhao, H. (2011). A new fluorescence complementation biosensor for detection of estrogenic compounds. Biotechnol. Bioeng. 108, 2794-2803. doi: 10.1002/bit.23254

Meisel, R. L., and Joppa, M. A. (1994). Conditioned place preference in female hamsters following aggressive or sexual encounters. Physiol. Behav. 56, 1115-1118. doi: 10.1016/0031-9384(94)90352-2

Mitani, J. C., Watts, D. P., and Amsler, S. J. (2010). Lethal intergroup aggression leads to territorial expansion in wild chimpanzees. Curr. Biol. 20, R507-R508. doi: 10.1016/j.cub.2010.04.021

Mitchell, J. P., Macrae, C. N., and Banaji, M. R. (2006). Dissociable medial prefrontal contributions to judgments of similar and dissimilar others. Neuron 50, 655-663. doi: 10.1016/j.neuron.2006.03.040

Mitra, S. W., Hoskin, E., Yudkovitz, J., Pear, L., Wilkinson, H. A., Hayashi, S., et al. (2003). Immunolocalization of estrogen receptor beta in the mouse brain: comparison with estrogen receptor alpha. Endocrinology 144, 2055-2067. doi: 10.1210/en.2002-221069

Moga, M. M., Weis, R. P., and Moore, R. Y. (1995). Efferent projections of the paraventricular thalamic nucleus in the rat. J. Comp. Neurol. 359, 221-238. doi: 10.1002/cne.903590204

Morley, P., Whitfield, J. F., Vanderhyden, B. C., Tsang, B. K., and Schwartz, J. L. (1992). A new, nongenomic estrogen action: the rapid release of intracellular calcium. Endocrinology 131, 1305-1312. doi: 10.1210/endo.131.3.1505465

Mos, J. J. H., Lammers, C. M., Vanderpoel, A. M., Bermond, B., Meelis, W., and Kruk, M. R. (1983). Effects of midbrain central gray lesions on spontaneous and electrically induced aggression in the rat. Aggress. Behav. 9, 133-155. doi: 10.1002/1098-2337(1983)9:2<133::AID-AB2480090205>3.0.CO;2-H

Mos, J., Kruk, M. R., Vanderpoel, A. M., and Meelis, W. (1982). Aggressive-behavior induced by electrical-stimulation in the midbrain central gray of male-rats. Aggress. Behav. 8, 261-284. doi: 10.1002/1098-2337(1982)8:3<261::AID-AB2480080304>3.0.CO;2-N

Moss, R. L., Chan, A., and Dudley, C. A. (1985). Hyperprolactinemia: its electrophysiologic and pharmacologic effect on neurons of the ventromedial nucleus of the hypothalamus. Brain Res. 346, 301-309. doi: 10.1016/0006-8993(85)90864-9

Motta, S. C., Carobrez, A. P., and Canteras, N. S. (2017). The periaqueductal gray and primal emotional processing critical to influence complex defensive responses, fear learning and reward seeking. Neurosci. Biobehav. Rev. 76, 39-47. doi: 10.1016/j.neubiorev.2016.10.012

Motta, S. C., Goto, M., Gouveia, F. V., Baldo, M. V., Canteras, N. S., and Swanson, L. W. (2009). Dissecting the brain's fear system reveals the hypothalamus is critical for responding in subordinate conspecific intruders. Proc. Natl. Acad. Sci. U.S.A. 106, 4870-4875. doi: 10.1073/pnas.0900939106

Motta, S. C., Guimarães, C. C., Furigo, I. C., Sukikara, M. H., Baldo, M. V., Lonstein, J. S., et al. (2013). Ventral premammillary nucleus as a critical sensory relay to the maternal aggression network. Proc. Natl. Acad. Sci. U.S.A. 110, 14438-14443. doi: 10.1073/pnas.1305581110

Mouton, L. J., and Holstege, G. (1994). The periaqueductal gray in the cat projects to lamina VIII and the medial part of lamina VII throughout the length of the spinal cord. Exp. Brain Res. 101, 253-264. doi: 10.1007/BF00228745

Mugford, R. A., and Nowell, N. W. (1970). Pheromones and their effect on aggression in mice. Nature 226, 967-968. doi: 10.1038/226967a0

Nelson, R. J., and Trainor, B. C. (2007). Neural mechanisms of aggression. Nat. Rev. Neurosci. 8, 536-546. doi: 10.1038/nrn2174

Niederkofler, V., Asher, T. E., Okaty, B. W., Rood, B. D., Narayan, A., Hwa, L. S., et al. (2016). Identification of serotonergic neuronal modules that affect aggressive behavior. Cell Rep. 17, 1934-1949. doi: 10.1016/j.celrep.2016.10.063
Nishizuka, M., and Pfaff, D. W. (1989). Intrinsic synapses in the ventromedial nucleus of the hypothalamus: an ultrastructural study. J. Comp. Neurol. 286, 260-268. doi: 10.1002/cne.902860210

Novotny, M., Harvey, S., Jemiolo, B., and Alberts, J. (1985). Synthetic pheromones that promote inter-male aggression in mice. Proc. Natl. Acad. Sci. U.S.A. 82, 2059-2061. doi: 10.1073/pnas.82.7.2059

Oka, Y., Ye, M., and Zuker, C. S. (2015). Thirst driving and suppressing signals encoded by distinct neural populations in the brain. Nature 520, 349-352. doi: 10.1038/nature14108

Oomura, Y., Aou, S., Koyama, Y., Fujita, I., and Yoshimatsu, H. (1988). Central control of sexual behavior. Brain Res. Bull. 20, 863-870. doi: 10.1016/0361-9230(88)90103-7

Oomura, Y., Yoshimatsu, H., and Aou, S. (1983). Medial preoptic and hypothalamic neuronal activity during sexual behavior of the male monkey. Brain Res. 266, 340-343. doi: 10.1016/0006-8993(83)90666-2

Padilla, S. L., Qiu, J., Soden, M. E., Sanz, E., Nestor, C. C., Barker, F. D., et al. (2016). Agouti-related peptide neural circuits mediate adaptive behaviors in the starved state. Nat. Neurosci. 19, 734-741. doi: 10.1038/nn.4274

Pan, Y., Xu, L., Young, K. A., Wang, Z., and Zhang, Z. (2010). Agonistic encounters and brain activation in dominant and subordinate male greater long-tailed hamsters. Horm. Behav. 58, 478-484. doi: 10.1016/j.yhbeh.2010.05.001

Pardo-Bellver, C., Cádiz-Moretti, B., Novejarque, A., Martínez-García, F., and Lanuza, E. (2012). Differential efferent projections of the anterior, posteroventral, and posterodorsal subdivisions of the medial amygdala in mice. Front. Neuroanat. 6:33. doi: 10.3389/fnana.2012.00033

Petrovich, G. D., Risold, P. Y., and Swanson, L. W. (1996). Organization of projections from the basomedial nucleus of the amygdala: a PHAL study in the rat. J. Comp. Neurol. 374, 387-420. doi: 10.1002/(SICI)1096-9861(19961021)374:3<387::AID-CNE6>3.0.CO;2-Y

Pfaff, D. W., and Sakuma, Y. (1979a). Deficit in the lordosis reflex of female rats caused by lesions in the ventromedial nucleus of the hypothalamus. J. Physiol. Lond. 288, 203-210.

Pfaff, D. W., and Sakuma, Y. (1979b). Facilitation of the lordosis reflex of female rats from the ventromedial nucleus of the hypothalamus. J. Physiol. Lond. 288, 189-202.

Potegal, M., Ferris, C. F., Hebert, M., Meyerhoff, J., and Skaredoff, L. (1996). Attack priming in female Syrian golden hamsters is associated with a c-foscoupled process within the corticomedial amygdala. Neuroscience 75, 869-880. doi: 10.1016/0306-4522(96)00236-9

Pradhan, D. S., Newman, A. E., Wacker, D. W., Wingfield, J. C., Schlinger, B. A., and Soma, K. K. (2010). Aggressive interactions rapidly increase androgen synthesis in the brain during the non-breeding season. Horm. Behav. 57, 381-389. doi: 10.1016/j.yhbeh.2010.01.008

Pro-Sistiaga, P., Mohedano-Moriano, A., Ubeda-Bañon, I., Del Mar ArroyoJimenez, M., Marcos, P., Artacho-Pérula, E., et al. (2007). Convergence of olfactory and vomeronasal projections in the rat basal telencephalon. J. Comp. Neurol. 504, 346-362. doi: 10.1002/cne.21455

Putkonen, P. T. (1966). Attack elicited by forebrain and hypothalamic stimulation in the chicken. Experientia 22, 405-407. doi: 10.1007/BF019 01167

Remedios, R., Kennedy, A., Zelikowsky, M., Grewe, B. F., Schnitzer, M. J., and Anderson, D. J. (2017). Social behaviour shapes hypothalamic neural ensemble representations of conspecific sex. Nature 550, 388-392. doi: $10.1038 /$ nature23885

Risold, P. Y., and Swanson, L. W. (1997). Connections of the rat lateral septal complex. Brain Res. Brain Res. Rev. 24, 115-195. doi: 10.1016/S0165-0173(97)00009-X

Sakurai, K., Zhao, S., Takatoh, J., Rodriguez, E., Lu, J., Leavitt, A. D., et al. (2016). Capturing and manipulating activated neuronal ensembles with CANE delineates a hypothalamic social-fear circuit. Neuron 92, 739-753. doi: 10.1016/j.neuron.2016.10.015

Schurger, A., Sitt, J. D., and Dehaene, S. (2012). An accumulator model for spontaneous neural activity prior to self-initiated movement. Proc. Natl. Acad. Sci. U.S.A. 109, E2904-E2913. doi: 10.1073/pnas.1210467109

Shimura, T., Yamamoto, T., and Shimokochi, M. (1994). The medial preoptic area is involved in both sexual arousal and performance in male-rats reevaluation of neuron activity in freely moving. Anim. Brain Res. 640, 215-222. doi: 10.1016/0006-8993(94)91875-9 
Siegel, A. T., Roeling, A. P., Gregg, T. R., and Kruk, M. R. (1999). Neuropharmacology of brain-stimulation-evoked aggression. Neurosci. Biobehav. R 23, 359-389. doi: 10.1016/S0149-7634(98)00040-2

Siegel, A., and Pott, C. B. (1988). Neural substrates of aggression and flight in the cat. Prog. Neurobiol. 31, 261-283. doi: 10.1016/0301-0082(88)90015-9

Siegel, A., and Skog, D. (1970). Effects of electrical stimulation of the septum upon attack behavior elicited from the hypothalamus in the cat. Brain Res. 23, 371-380. doi: 10.1016/0006-8993(70)90063-6

Silva, B. A., Mattucci, C., Krzywkowski, P., Murana, E., Illarionova, A., Grinevich, V., et al. (2013). Independent hypothalamic circuits for social and predator fear. Nat. Neurosci. 16, 1731-1733. doi: 10.1038/nn.3573

Simerly, R. B., and Swanson, L. W. (1988). Projections of the medial preoptic nucleus: a Phaseolus vulgaris leucoagglutinin anterograde tract-tracing study in the rat. J. Comp. Neurol. 270, 209-242. doi: 10.1002/cne.902700205

Simerly, R. B., Chang, C., Muramatsu, M., and Swanson, L. W. (1990). Distribution of androgen and estrogen receptor mRNA-containing cells in the rat brain: an in situ hybridization study. J. Comp. Neurol. 294, 76-95. doi: $10.1002 /$ cne. 902940107

Soden, M. E., Miller, S. M., Burgeno, L. M., Phillips, P. E., Hnasko, T. S., and Zweifel, L. S. (2016). Genetic isolation of hypothalamic neurons that regulate context-specific male social behavior. Cell Rep. 16, 304-313. doi: 10.1016/j.celrep.2016.05.067

Soma, K. K., Alday, N. A., Hau, M., and Schlinger, B. A. (2004). Dehydroepiandrosterone metabolism by 3beta-hydroxysteroid dehydrogenase/Delta5-Delta4 isomerase in adult zebra finch brain: sex difference and rapid effect of stress. Endocrinology 145, 1668-1677. doi: 10.1210/en.2003-0883

Soyka, M., Graz, C., Bottlender, R., Dirschedl, P., and Schoech, H. (2007). Clinical correlates of later violence and criminal offences in schizophrenia. Schizophr. Res. 94, 89-98. doi: 10.1016/j.schres.2007.03.027

Takahashi, A., Nagayasu, K., Nishitani, N., Kaneko, S., and Koide, T. (2014). Control of intermale aggression by medial prefrontal cortex activation in the mouse. PLoS ONE 9:e94657. doi: 10.1371/journal.pone.0094657

Tang, H., Wu, G. S., Xie, J., He, X., Deng, K., Wang, H., et al. (2016). Brain-wide map of projections from mice ventral subiculum. Neurosci. Lett. 629, 171-179. doi: 10.1016/j.neulet.2016.07.014

Thompson, T. I. (1963). Visual reinforcement in siamese fighting fish (bettasplendens). Am. Psychol. 18, 416-416.

Tohyama, M., Sakai, K., Touret, M., Salvert, D., and Jouvet, M. (1979). Spinal projections from the lower brain stem in the cat as demonstrated by the horseradish peroxidase technique. II. Projections from the dorsolateral pontine tegmentum and raphe nuclei. Brain Res. 176, 215-231. doi: 10.1016/0006-8993(79)90980-6

Tornatzky, W., Cole, J. C., and Miczek, K. A. (1998). Recurrent aggressive episodes entrain ultradian heart rate and core temperature rhythms. Physiol. Behav. 63, 845-853. doi: 10.1016/S0031-9384(98)00008-0

Trainor, B. C., Finy, M. S., and Nelson, R. J. (2008). Rapid effects of estradiol on male aggression depend on photoperiod in reproductively non-responsive mice. Horm. Behav. 53, 192-199. doi: 10.1016/j.yhbeh.2007.09.016

Trainor, B. C., Lin, S., Finy, M. S., Rowland, M. R., and Nelson, R. J. (2007). Photoperiod reverses the effects of estrogens on male aggression via genomic and nongenomic pathways. Proc. Natl. Acad. Sci. U.S.A. 104, 9840-9845. doi: 10.1073/pnas.0701819104

Turnboug, P. D., and Lloyd, K. E. (1973). Operant responding in siamese fighting fish (betta-splendens) as a function of schedule of reinforcement and visual reinforcers. J. Exp. Anal. Behav. 20, 355-362. doi: 10.1901/jeab.1973.20-355

Ubuka, T., and Tsutsui, K. (2014). Review: neuroestrogen regulation of sociosexual behavior of males. Front. Neurosci. 8:323. doi: 10.3389/fnins.2014.00323

Vasudevan, N., and Pfaff, D. W. (2008). Non-genomic actions of estrogens and their interaction with genomic actions in the brain. Front. Neuroendocrin. 29, 238-257. doi: 10.1016/j.yfrne.2007.08.003
Wang, F., Zhu, J., Zhu, H., Zhang, Q., Lin, Z., and Hu, H. (2011). Bidirectional control of social hierarchy by synaptic efficacy in medial prefrontal cortex. Science 334, 693-697. doi: 10.1126/science.1209951

Wang, L., Chen, I. Z., and Lin, D. (2015). Collateral pathways from the ventromedial hypothalamus mediate defensive behaviors. Neuron 85 , 1344-1358. doi: 10.1016/j.neuron.2014.12.025

Wang, R., Macmillan, L. B., Fremeau, R. T. Jr., Magnuson, M. A., Lindner, J., and Limbird, L. E. (1996). Expression of alpha 2-adrenergic receptor subtypes in the mouse brain: evaluation of spatial and temporal information imparted by $3 \mathrm{~kb}$ of $5^{\prime}$ regulatory sequence for the alpha $2 \mathrm{~A} \mathrm{AR}$-receptor gene in transgenic animals. Neuroscience 74, 199-218. doi: 10.1016/0306-4522(96)0 0116-9

Weiner, D. M., Levey, A. I., Sunahara, R. K., Niznik, H. B., O’Dowd, B. F., Seeman, P., et al. (1991). D1 and D2 dopamine receptor mRNA in rat brain. Proc. Natl. Acad. Sci. U.S.A. 88, 1859-1863. doi: 10.1073/pnas.88.5.1859

Wells, M. F., Wimmer, R. D., Schmitt, L. I., Feng, G., and Halassa, M. M. (2016). Thalamic reticular impairment underlies attention deficit in Ptchd1(Y/-) mice. Nature 532, 58-63. doi: 10.1038/nature17427

Wong, L. C., Wang, L., D'Amour, J. A., Yumita, T., Chen, G., Yamaguchi, T., et al. (2016). Effective modulation of male aggression through lateral septum to medial hypothalamus projection. Curr. Biol. 26, 593-604. doi: 10.1016/j.cub.2015.12.065

Wright, D. E., Seroogy, K. B., Lundgren, K. H., Davis, B. M., and Jennes, L. (1995). Comparative localization of serotonin1A, 1C, and 2 receptor subtype mRNAs in rat brain. J. Comp. Neurol. 351, 357-373. doi: 10.1002/cne.9035 10304

Xu, X., Coats, J. K., Yang, C. F., Wang, A., Ahmed, O. M., Alvarado, M., et al. (2012). Modular genetic control of sexually dimorphic behaviors. Cell 148, 596-607. doi: 10.1016/j.cell.2011.12.018

Yang, C. F., Chiang, M. C., Gray, D. C., Prabhakaran, M., Alvarado, M., Juntti, S. A., et al. (2013). Sexually dimorphic neurons in the ventromedial hypothalamus govern mating in both sexes and aggression in males. Cell 153, 896-909. doi: $10.1016 /$ j.cell.2013.04.017

Yang, T., Yang, C. F., Chizari, M. D., Maheswaranathan, N., Burke, K. J. Jr., Borius, M., et al. (2017). Social control of hypothalamus-mediated male aggression. Neuron 95, 955.e4-970.e4. doi: 10.1016/j.neuron.2017.06.046

Young, L. J., Muns, S., Wang, Z., and Insel, T. R. (1997). Changes in oxytocin receptor mRNA in rat brain during pregnancy and the effects of estrogen and interleukin-6. J. Neuroendocrinol. 9, 859-865. doi: 10.1046/j.1365-2826.1997.00654.x

Yu, Q., Teixeira, C. M., Mahadevia, D., Huang, Y., Balsam, D., Mann, J. J., et al. (2014). Dopamine and serotonin signaling during two sensitive developmental periods differentially impact adult aggressive and affective behaviors in mice. Mol. Psychiatry 19, 688-698. doi: 10.1038/mp.2014.10

Zhou, T., Zhu, H., Fan, Z., Wang, F., Chen, Y., Liang, H., et al. (2017). History of winning remodels thalamo-PFC circuit to reinforce social dominance. Science 357, 162-168. doi: 10.1126/science.aak9726

Zimmerman, C. A., Lin, Y. C., Leib, D. E., Guo, L., Huey, E. L., Daly, G. E., et al. (2016). Thirst neurons anticipate the homeostatic consequences of eating and drinking. Nature 537, 680-684. doi: 10.1038/nature18950

Conflict of Interest Statement: The authors declare that the research was conducted in the absence of any commercial or financial relationships that could be construed as a potential conflict of interest.

Copyright $\odot 2017$ Hashikawa, Hashikawa, Falkner and Lin. This is an open-access article distributed under the terms of the Creative Commons Attribution License (CC $B Y)$. The use, distribution or reproduction in other forums is permitted, provided the original author(s) or licensor are credited and that the original publication in this journal is cited, in accordance with accepted academic practice. No use, distribution or reproduction is permitted which does not comply with these terms. 